\title{
Ultraviolet Forecasting in Thailand
}

\author{
Sumridh Sudhibrabha ${ }^{a^{*}}$, Robert Harold Buchanan Exell a nd Dusadee Sukawat ${ }^{\mathrm{b}}$
}

a J oint Graduate School of Energy and Environment, King Mongkut's University of Technology Thonburi, Bangkok 10140.

b Department of Mathematics, Faculty of Science, King Mongkut's University of Technology Thonburi, Bangkok 10140.

* Corresponding author, E-mail: sumridh@metnettmd.go.th

Received 13 May 2005

Accepted 27 Dec 2005

\begin{abstract}
Total ozone and erythemal UV models have been created for UV Index forecasting in Thailand. Versions of an ozone model for Chiangmai, U bon Ratchathani, Bangkok and Songkhla and a UV model for Bangkok and Songkhla are available for operation on a daily basis. The procedure is to forecast ozone from upper air data, and then calculate the forecast erythemal UV irradiance from the ozone forecast. In the ozone models, a linear regression technique was used with fifteen coefficients for temperature and dynamic height at the $100 \mathrm{hPa}$ and $50 \mathrm{hPa}$ levels where the ozone exists and daily balloon observations are made. Simple ozone models were also developed for use in the areas without upper air observations. The data are in the form of time series over three consecutive days. The UV models were obtained from Brewer UV data from Bangkok and Songkhla fitted to a non-linear three dimensional equation which is a function of ozone and its air mass to obtain five coefficients for the empirical formula. The models are used to estimate cloud-free values of the UV Index over the different areas of the country. The output of the erythemal UV for a clear sky is converted to the UV Index. The UV Index is then used to select one of five categories for issuing to the public every noon. Reductions of the UV Index for cloudy skies are also given. The average accuracy of the models is acceptable as the squares of the correlation coefficients $\left(R^{2}\right)$ are 0.88 and 0.99 for the ozone and UV models respectively, while the mean absolute percentage errors are $1.5 \%$ and $7.5 \%$ for the ozone and UV forecasting respectively.
\end{abstract}

KFword: ozone, ultraviolet, UV Index, erythemal UV, cloud modification factor, aerosol optical depth.

\section{INIRODUCTION}

An appropriate forecast method has been developed to provide daily information on ultraviolet radiation at ground level in four areas of Thailand. ${ }^{1,2,3}$ The purpose of this paper is to give full details of the method used, and of the current measurement on which the forecasts are based. The procedure is to forecast ozone from upper air data by a modification of the method developed in the University of Thessaloniki, and then cal culate theforecast erythemal UV irradiancefrom theozoneforecast by the Canadian method with new coefficients based on observations in Thailand.

\section{Ultraviolet Index}

TheUItraviolet Index (UVI) 4 is a simplemeasure of theul traviolet (UV) radiation level at theEarth's surface and an indicator of the potential for skin damage. It serves as an important vehicleto raise public awareness and to alert people to the need to adopt protective measures when exposed to UV radiation. TheUVI was developed through an international effort by theWorld
$\mathrm{H}$ ealth O rganization (W HO) in collaboration with the United NationsEnvironment Programme(UNEP), the World Meteorological Organization (WMO), the International Commission on N on-Ionizing Radiation Protection (ICNIRP) and the German Federal Office for Radiation Protection.

The calculation of the UVI based on modeling of erythemal irradiance, which depends on solar zenith angle, altitude, ozone, surface albedo, aerosols and clouds. The erythemally weighted irradiance, ${ }^{5} \mathrm{E}_{\mathrm{CIE}}$, is defined by the integral

$$
E_{C I E}=\int_{250 \mathrm{~nm}}^{400 \mathrm{~nm}} E_{G}(\lambda) C(\lambda) \mathrm{d} \lambda,
$$

where $E_{G(\lambda)}$ is the global spectral irradiance and $C(\lambda)$ is the CIE erythemal effectiveness function proposed by M ckinlay and Diffey ${ }^{6}$ in 1987. A UVI value is the result of multiplying the erythemally weighted irradiance $\left(\mathrm{W} / \mathrm{m}^{2}\right)$ by 40 . The typical UVI levels in Thailand usually range from 0 to 14. The UVI for different amounts of cloud and different altitudes is calculated using the following equation ${ }^{7}$

$$
\mathrm{UVI}=\mathrm{UVI}_{0} \times \mathrm{CMF}(1+0.08 \Delta \mathrm{H}) \text {, }
$$


where UVI ${ }_{0}$ is the UVI for a clear sky at a reference altitude, CMF is a Cloud Modification Factor, and $\Delta \mathrm{H}$ is the altitude $(\mathrm{km})$ above the reference al titude.

\section{Factors Affecting the Solar UV Radiation Flux ${ }^{8}$}

Zenith Angle of theSun. Theraysfrom the sun are attenuated by scattering and absorption from gases and particles in the atmosphere. The nearer the sun is to thezenith, thehigher is theintensity of UV radiation at the surface.

Atmospheric Ozonemoleculesabsorb someof the UV radiation that would otherwise reach the Earth's surface. Therefore, themoredepleted theozoneis, the stronger is the UV intensity.

Aerosols generally decrease the amount of UV radiation at the surface by atmospheric scattering and absorption.

Clouds can increase and decrease UV radiation by reflection and absorption processes respectively. The levelsarehighest under cloudlessskiesand lower under cloudy, rainy and hazy skies.

Altitude. Athigher altitudesthethinner atmosphere absorbs less UV radiation. W ith every 1000 meters increasein altitu de, UV radiation levels increase by 10 $12 \%$. $^{8}$

Latitude. TheUV radiation is highest in low latitudes because of higher sun elevations.

Ground Reflection. UV radiation is reflected or scattered by different surfaces to varying extents. For example, fresh snow, dry beach sand, and sea foam can reflect as much as $80 \%, 15 \%$ and $25 \%$, respectively ${ }^{8}$.

\section{Materials and Methods}

Theozoneand UV dataused are measured regularly by the Thai M eteorological Department (TMD) in the framework of the W MO Global Atmosphere Watch programme. The measurements are made using a ground-based Dobson spectrophotometer for thetotal column ozoneand a Brewer spectrophotometer (Fig.1) for UVA (315-400 nm) and UVB (285-315 nm).

\section{Total Column Ozone}

The Brewer spectrophotometer is designed to measure the light intensity for determining the total ozone, sulphur dioxide, nitrogen dioxide and UV spectra. The first instrument was designed by Alan Brewer who worked at the Sub-department of Atmospheric, Oceanic and Planetary Physics, University of Oxford during 1948-1962. In modern instruments, sun tracking, ap propriatefilter selection, wavelength calibration and data logging are managed through internal electronics and a compatible PC host computer. Control software for the host computer provides twenty-four hour scheduling.
Total ozoneand sulphur dioxide measurements are madeat fivewavelengths, namely $306.3,310.1,313.5$, 316.8 and $320.1 \mathrm{~nm}$. These measurements are expressed in Dobson Units (100 D.U. $=0.1 \mathrm{~atm}-\mathrm{cm}$ ).

Themeasured intensity of direct sunlight at each of the five wavel engths is given by

$$
\log \mathrm{I}_{\lambda}=\log \mathrm{I}_{0 \lambda}-\beta_{\lambda} \mathrm{m}-\delta_{\lambda} \sec \theta-\alpha_{\lambda} \mathrm{O}_{3} \mu-\alpha_{\lambda^{\prime}} \mathrm{SO}_{2} \mu^{\prime},
$$

\section{where}

$\mathrm{I}_{\lambda}$

wavelength $\lambda$,

$I_{0 \lambda}$

wavelength $\lambda$,

wavelength $\lambda$,

$\delta_{\lambda}$

at wavelength $\lambda$,

$\alpha_{\lambda}$

is measured light intensity at

is extra terrestrial light intensity at

is Rayleigh scattering coefficient at wavelength $\lambda$

$\begin{array}{cl}0_{3} & \text { is amount of total column ozone, } \\ \alpha^{\prime} \lambda & \text { is sulphur dioxide absorption }\end{array}$ coefficient at $\lambda$,

$\mathrm{SO}_{2} \quad$ is total sulphur dioxide amount,

$\mathrm{m}, \sec \theta, \mu, \mu$ arerelativeair masses for the Rayleigh, aerosol, ozoneand sulphur dioxideterms, respectively.

\section{Ultraviolet}

TheBrewer spectrophotometer measures theglobal solar UV irradiance between $286.5-363.0 \mathrm{~nm}$ at $0.5 \mathrm{~nm}$ wavelength steps and resolution. Non-weighted spectral values of UV radiation from a hemispherical field of view are determined for each wavelength increment as $\mathrm{W} / \mathrm{m}^{2}$. Erythemally weighted irradiance integrated over the wavelength range $\left(\mathrm{mW} / \mathrm{m}^{2}\right)$ and over time $\left(\mathrm{J} / \mathrm{m}^{2}\right.$ per day) is also available.

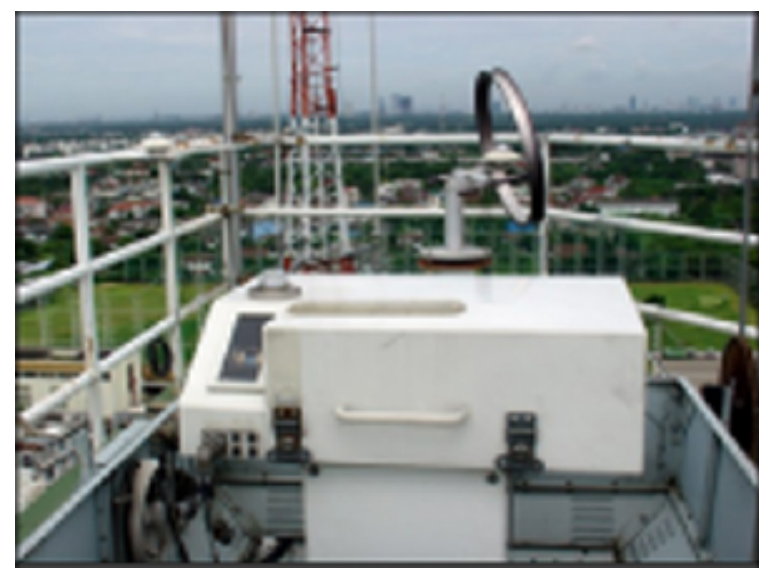

Fig 1. Brewer spectrophotometer MKIV used at TMD 


\section{Aerosol Optical Depth}

Aerosol optical depth (AOD) is a consequence of scattering and absorption of solar radiation by aerosols; although ozone absorption and molecular scattering are much more important, aerosols also have an influence on UV radiation.

AOD can be measured by the Brewer spectrophotometer at UV wavelengths. A small change of AOD can give a big change in the UV flux. The calculation of $A O D^{9}$ in the UV wavelength range is:

$$
\tau_{\text {aer }}=\tau_{\text {tot }}-\tau_{\text {ray }}-\tau_{03}-\tau_{\mathrm{SO} 2} \text {, }
$$

where

$\tau_{\text {aer }}$ is the aerosol optical depth,

$\tau_{\text {tot }}$ is atmospheric total optical depth,

$\tau_{\text {ray }}$ is optical depth due to Rayleigh scattering,

$\tau_{03}$ is optical depth due to ozone absorption,

$\tau_{\mathrm{SO}_{2}}$ is optical depth due to sulphur dioxide absorption,

Thetotal optical depth for avertical path is defined ${ }^{10}$

$$
\text { by } \tau_{\text {tot }}=\frac{1}{\mathrm{~m}} \ln \left(\frac{\mathrm{I}_{0}}{\mathrm{l}}\right) \text {, }
$$

where 1 is intensity of radiation at the point of observation, $I_{0}$ is intensity of radiation at thetop of the atmosphereand $m$ is relativeair mass taking into account the direct beam slant path through the atmosphere. Themolecular optical depth $\tau_{\text {ray }}$ depends ${ }^{11}$ only upon surface pressure and wavelength:

$$
\tau_{\text {ray }}=\frac{0.008569 \lambda^{-4}\left(1+0.0113 \lambda^{-2}+0.00013 \lambda^{-4}\right) p}{1013.25}
$$

where $\lambda$ is the wavelength $(\mu \mathrm{m})$, and $p$ is the atmospheric pressure in $\mathrm{hPa}$ at the site.

The ozone optical depth is given by

$\tau_{03}=0_{3} \kappa_{03}(\lambda) \tau_{03}$

where $\mathrm{O}_{3}$ is thetotal column amount of ozone(atm$\mathrm{cm})$ and $\kappa_{03}$ is the ozoneabsorption coefficient $\left(\mathrm{cm}^{-1}\right)$.

The sulphur dioxide optical depth is given by

$\tau_{\mathrm{SO}_{2}}=\mathrm{SO}_{2} \kappa_{\mathrm{SO}_{2}}(\lambda)$,

where $\mathrm{SO}_{2}$ is the total column amount of sulphur dioxide (atm- $\mathrm{cm})$, and $\kappa_{\mathrm{SO} 2}$ is the $\mathrm{SO}_{2}$ absorption coefficient $\left(\mathrm{cm}^{-1}\right)$.

\section{UV Forecasting Procedure}

The UV forecasting procedure is illustrated in Fig. 2. The sections below give details of the models used in this procedure.

Thefirst step is predicting total ozonefrom current ozone measurements and other meteorological observations. The predicted total ozone value is then substituted into a clear sky UV model in order to generate the clear sky erythemal and UVI. A cloud modification factor from the current weather forecast can beapplied to produceaUVI forecast for thepublic.

\section{Ozone Modeling}

The new methodology in ozone forecasting uses multiplelinear regressions of timeseriesin an equation similar to the equation developed at the Laboratory of Atmospheric Physics (LAP), University of Thessaloniki ${ }^{12}$. The total ozone models are based on physical assumptions for ozone formation. When oxygen molecules are broken by UV radiation and release energy to the atmosphere, the consequent effectson air temperature, pressure, and ozoneamounts can occur within a couple of days. U pper air data have proved this assumption. Themodel isobtained by fitting measured data using a linear regression technique. The total ozone on the day of the prediction is forecast from its values on the previous two days together with temperatureand dynamic height at the $50 \mathrm{hPa}$ and 100 hPa pressurelevels over threeconsecutive days ending with the current day.

For the work described in this paper the temperatures and dynamic heights werecollected from daily balloon observations, and the total ozone values were from ground-based Dobson ozone spectrophotometer measurements made at Bangkok $(13.67 \mathrm{~N}, 100.62 \mathrm{E})$, and satellite data retrieved from the NASA Total O zoneM Mapping Spectrometer (TOMS) over Chiangmai $(18.78 \mathrm{~N}, 98.98 \mathrm{E})$ and Ubon Ratchathani (14.97N , 104.87E) during 1997-2000.

The multiple linear regression model used was:

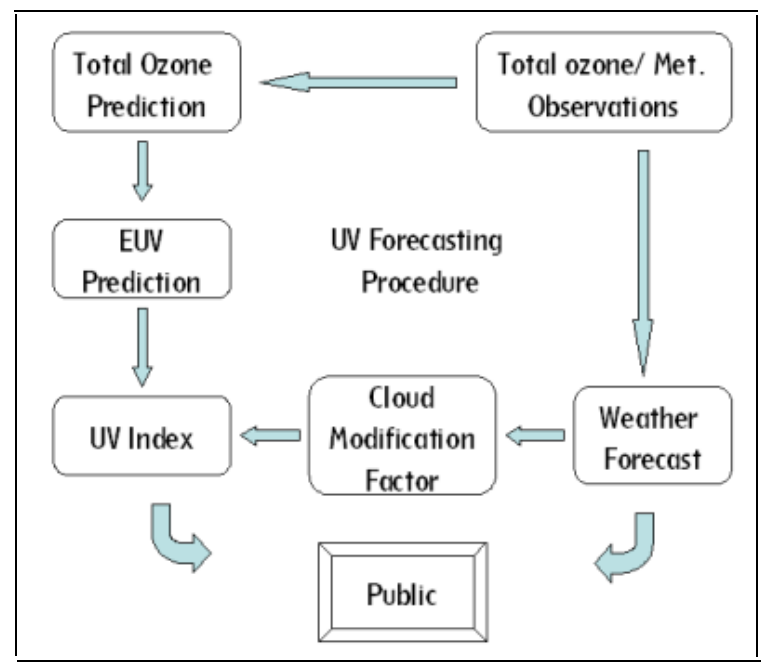

Fig 2. UV forecasting procedure. 


$$
\begin{aligned}
\mathrm{O}_{3}(\mathrm{i})= & \beta_{1}+\beta_{2} \mathrm{~T}_{50}(\mathrm{i})+\beta_{3} \phi_{50}(\mathrm{i})+\beta_{4} \mathrm{~T}_{100}(\mathrm{i})+ \\
& \beta_{5} \phi_{100}(\mathrm{i})+\beta_{6} \mathrm{O}_{3}(\mathrm{i}-1)+\beta_{7} \mathrm{~T}_{50}(\mathrm{i}-1)+ \\
& \beta_{8} \phi_{50}(\mathrm{i}-1)+\beta_{9} \mathrm{~T}_{100}(\mathrm{i}-1)+\beta_{10} \phi_{100}(\mathrm{i}-1)+ \\
& \beta_{11} \mathrm{O}_{3}(\mathrm{i}-2)+\beta_{12} \mathrm{~T}_{50}(\mathrm{i}-2)+\beta_{13} \phi_{50}(\mathrm{i}-2)+ \\
& \beta_{14} \mathrm{~T}_{100}(\mathrm{i}-2)+\beta_{15} \phi_{100}(\mathrm{i}-2)
\end{aligned}
$$

where

is the day for which the forecast is made,

$\mathrm{O}_{3}$ is the total column ozone in Dobson Units,

$\mathrm{T}_{50}$ to $\mathrm{T}_{100}$ aretemperatures at $50 \mathrm{hPa}$ and $100 \mathrm{hPa}$,

$\phi_{50}$ to $\phi_{100}$ are dynamic heights at $50 \mathrm{hPa}$ and $100 \mathrm{hPa}$, and

$\beta_{1}$ to $\beta_{15}$ are the coefficients.

\section{Simple Ozone Modeling}

Thesemodel swere devel oped from atime series of total ozone to be used at sites where no upper air observations were available. A simple model was run by the stepwise method in linear regression with some statistical applications. Thesignificant parameters are total ozone on the two previous days before the day of forecasting. Thetimeseries coefficients are $c_{1}, c_{2}$ and $\mathrm{C}_{3}$ in the following equation

$$
\mathrm{O}_{3}(\mathrm{i})=\mathrm{C}_{1}+\mathrm{C}_{2} \mathrm{O}_{3}(\mathrm{i}-1)+\mathrm{C}_{3} \mathrm{O}_{3}(\mathrm{i}-2) \text {. }
$$

\section{Ultraviolet Modeling}

Forecasts of the UVI are generated from local UV models which are created by a regression technique following the Canadian method ${ }^{13}$. The values of erythemal UV irradiance for a clear sky are calculated using the total ozone forecast $\mathrm{O}_{3}$.

The data used in modeling wereintegral erythemal UV irradiances from Brewer measurements made in the complete absence of cloud. The data were fitted to the following non-linear expression for EUV $\mathrm{E}_{0}$ as a function of ozone and its air mass to obtain the five coefficients $a, b, c, d$, and e in:

EUV $_{0}=C_{d} \cos \theta \exp \left(a+b \mu O_{3}+c \mu+d\left(\mu O_{3}\right)^{2}+e \mu^{2}\right)$

where

EUV $_{0}$ is erythemal UV flux at the surface under a clear sky $\left(\mathrm{mW} / \mathrm{m}^{2}\right)$,

$\mathrm{C}_{d}$ is the Earth-Sun distance correction factor,

$\mathrm{O}_{3}$ is column ozone amount in atm- $\mathrm{cm}$,

$\mu$ is air mass of ozone, and

$\theta \quad$ is zenith angle.

The coefficients $a, b, c, d$, and e were found by the followingsteps:

(1) Daily averaged values of the AOD derived from Brewer ozone direct sun measurementsin theUV range at $306.3 \mathrm{~nm}$ werecollected. The values obtained wereclassified into: completely clear sky with $\tau_{\text {aer }}<0.2$, averageclear sky with $0.2 \leq \tau_{\text {aer }} \leq 0.5$, and polluted sky with $\tau_{\text {aer }}>0.5$. Themaximum value of $\tau_{\text {aer }}$ observed was

\subsection{0 in Bangkok and 1.78 in Songkhla.}

(2) Erythemal UV irradiance was measured regularly by Brewer spectrophotometers at Bangkok and Songkhla. Data for 2000-2004 at Bangkok and 2001-2004 at Songkhla were used for the modeling. Clear sky data were selected by screening out days on which clouds were observed visually and the graphs of EUV irradiance versus time were not smooth. The integral of erythemal weighted irradiancewascalculated automatical ly from the raw data by the software of the Brewer spectrophotometer. It was found from the measurements that themaximum EUV $V_{0}$ isusually in the range of $250-350 \mathrm{~mW} / \mathrm{m}^{2}$ in summer on a clear day. In Fig. 3 plots of EUV $V_{0}$ are shown for two different aerosol conditions.

(3) Threemethods wereused to obtain data on total

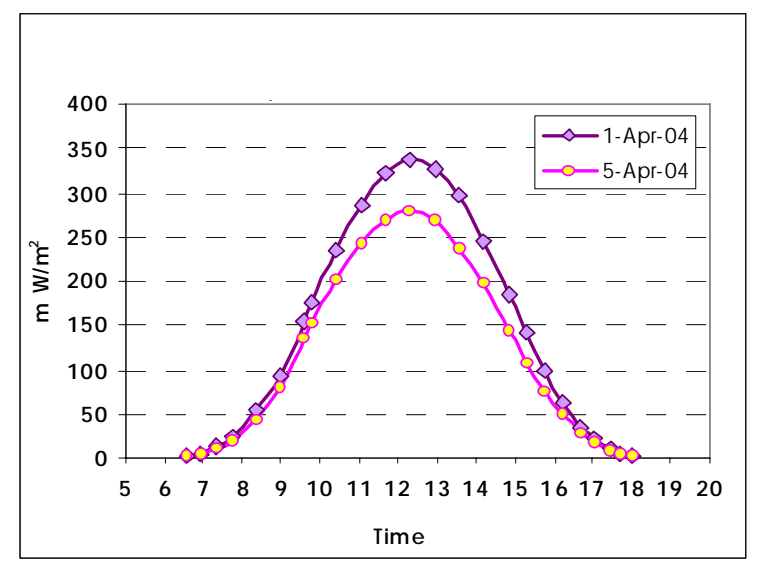

Fig 3. Values of EUV $V_{0}$ measured as a function of time for two clear days in Songkhla.

column ozone, namely Brewer spectrophotometer measurements, Dobson ozone spectrophotometer measurements, and TOMS satellite data. The Brewer spectrophotometer measurements were used for ultraviolet modeling in equation (5), and the other measurements were used for ozone prediction in equation (4).

(4) The air mass $\mu$ for use in equation (5) was calculated from the zenith angle $\theta$ of the sun by the equation

$$
\mu=\left(\cos \left(\arcsin \left(\frac{\mathrm{R}}{\mathrm{R}+\mathrm{h}} \sin \theta\right)\right)\right)^{-1}
$$

where $R$ is the radius of the Earth $(6371 \mathrm{~km})$ and $\mathrm{h}$ is the height of the ozone layer $(22 \mathrm{~km})$.

(5) TheEarth-Sun distance correction factor ${ }^{13}$, was calculated from

$$
\begin{aligned}
C_{d}= & 1.000110+0.034221 \cos (y)+0.001280 \sin (y)+ \\
& 0.000719 \cos (2 y)+0.000077 \sin (2 y),
\end{aligned}
$$


Table 1. Cloud Modification Factors.

\begin{tabular}{ccccccc}
\hline Cloud Amount & Clear(0-2) & Partly Cloud(3-5) & Cloudy(6-8) & Overcast(9-10) & Fog & Rain \\
\hline CMF & 1.0 & 0.9 & 0.7 & 0.3 & 0.4 & 0.2 \\
\hline
\end{tabular}

Table 2. Coefficients of the total column ozone model.

\begin{tabular}{cccccc}
\hline Var. & Coeff. & TO3CHM & TO3UBN & DO3BKK & TO3SKL \\
\hline constant & $\beta_{1}$ & 144.149 & 36.141 & -76.179 & -13.722 \\
$\mathrm{~T}_{50}(\mathrm{i})$ & $\beta_{2}$ & 0.065 & 0.051 & -0.047 & -0.168 \\
$\phi_{50}(\mathrm{i})$ & $\beta_{3}$ & -0.003 & 0.002 & 0.000 & -0.004 \\
$\mathrm{~T}_{100}(\mathrm{i})$ & $\beta_{4}$ & 0.208 & -0.042 & -0.042 & -0.012 \\
$\phi_{100}(\mathrm{i})$ & $\beta_{5}$ & -0.013 & -0.003 & 0.008 & 0.005 \\
$\mathrm{O}_{3}(\mathrm{i}-1)$ & $\beta_{6}$ & 0.534 & 0.562 & 0.629 & 0.413 \\
$\mathrm{~T}_{50}(\mathrm{i}-1)$ & $\beta_{7}$ & 0.117 & 0.141 & -0.153 & 0.223 \\
$\phi_{50}(\mathrm{i}-1)$ & $\beta_{8}$ & 0.011 & 0.001 & 0.000 & 0.001 \\
$\mathrm{~T}_{100}(\mathrm{i}-1)$ & $\beta_{9}$ & 0.038 & 0.047 & 0.018 & -0.036 \\
$\phi_{100}(\mathrm{i}-1)$ & $\beta_{10}$ & -0.012 & 0.000 & -0.006 & -0.001 \\
$\mathrm{O}_{3}(\mathrm{i}-2)$ & $\beta_{11}$ & 0.403 & 0.378 & 0.274 & 0.478 \\
$\mathrm{~T}_{50}(\mathrm{i}-2)$ & $\beta_{12}$ & 0.076 & -0.025 & 0.267 & -0.064 \\
$\phi_{50}(\mathrm{i}-2)$ & $\beta_{13}$ & -0.020 & -0.002 & 0.000 & 0.021 \\
$\mathrm{~T}_{100}(\mathrm{i}-2)$ & $\beta_{14}$ & 0.003 & 0.018 & 0.182 & 0.076 \\
$\phi_{100}(\mathrm{i}-2)$ & $\beta_{15}$ & 0.033 & 0.002 & 0.005 & -0.024 \\
\hline
\end{tabular}

$y=2 \pi($ Julian date -1$) / 365$

(6) The cosine of the zenith angle of the sun was calculated from

\section{$\cos \theta=\cos \delta \cos \omega \cos \phi+\sin \delta \sin \phi$}

where $\delta$ isthesolar declination, $\omega$ ishour angle, and $\phi$ islatitude.

(7) The quantity $f=\ln \left(\frac{E V_{0}}{C_{d} \cos \theta}\right) \quad$ was then calculated and fitted by the method of least squares to the non-linear regression formula

$\mathrm{f}=\mathrm{a}+\mathrm{b} \mu \mathrm{O}_{3}+\mathrm{c} \mu+\mathrm{d}\left(\mu \mathrm{O}_{3}\right)^{2}+\mathrm{e} \mu^{2}$ to find the coefficientsa, $b, c, d$, and $\mathrm{e}$ for usein equation (5).

\section{Cloud Modification Factor}

The cloud modification factors (CMF) for use in equation (2) developed by the European COST-7138 were applied to the daily data. The CM F values used with clear sky EUV 0 are shown in Table 1.

\section{REsULTS}

\section{Ozone Models}

Ozone models have been created for four areas. The coefficients from the study are given in Tables 2 to 5.

T0 3CHM isamodel fitted for Chiangmai, TO 3 UBN is for Ubon Ratchathani, DO 3BKK is for Bangkok, and TO 3SKL isfor Songkhla. Theinitial 'TO3' isfor TOMS

Table 3. Residuals analysis of total column ozone model.

\begin{tabular}{|c|c|c|c|c|c|}
\hline & T03CHM & TO3UBN & D03BKK & T03SKL & Avg. \\
\hline$R^{2}$ & 0.91 & 0.93 & 0.82 & 0.87 & 0.88 \\
\hline ME & -0.21 & 0.09 & -0.10 & 0.09 & -0.03 \\
\hline RMSE & 5.47 & 4.85 & 6.45 & 4.01 & 5.19 \\
\hline MAE & 4.37 & 3.79 & 4.91 & 3.13 & 4.05 \\
\hline MAPE & 1.66 & 1.43 & 1.91 & 1.17 & 1.54 \\
\hline
\end{tabular}


Table 4. Coefficients of simple ozone model.

\begin{tabular}{crrrr}
\hline Coefficient. & STO3CHM & ST03UBN & SD03BKK & ST0 3SKL \\
\hline$C_{1}$ & 12.175 & 6.622 & 20.704 & 7.996 \\
$C_{2}$ & 0.552 & 0.588 & 0.638 & 0.499 \\
$C_{3}$ & 0.404 & 0.389 & 0.282 & 0.472 \\
\hline
\end{tabular}

Table 5. Residuals analysis of simple ozone model.

\begin{tabular}{lrrrrr}
\hline \multicolumn{7}{c}{ ST03CHM STO3UBN } & SDO3BKK & ST03SKL & Avg. \\
\hline$R^{2}$ & 0.90 & 0.92 & 0.82 & 0.86 & 0.88 \\
ME & 0.15 & -0.06 & -0.01 & 0.04 & 0.03 \\
RMSE & 5.60 & 4.98 & 6.56 & 4.09 & 5.31 \\
MAE & 4.40 & 3.93 & 5.00 & 3.14 & 4.12 \\
MAPE & 1.67 & 1.48 & 1.94 & 1.17 & 1.56 \\
& & & & & \\
\hline
\end{tabular}

Table 6. Coefficients of the UV models.

\begin{tabular}{lcclll}
\hline Model & $\mathrm{a}$ & \multicolumn{2}{c}{$\mathrm{c}$} & $\mathrm{e}$ \\
\hline & & & & & \\
EUVBKK75 & 7.1471 & -0.6862 & -1.7255 & 0.025 & 0.2453 \\
EUVSKL75 & 7.3997 & -4.8813 & -0.5954 & 2.56 & 0.0647 \\
& & & & & \\
\hline
\end{tabular}

Table 7. Residual Analysis of the UV models.

\begin{tabular}{lccrrr}
\hline \multicolumn{1}{c}{ Model } & R $^{2}$ & ME & RMSE & MAE & MAPE \\
\hline EUVBKK75 & 0.99 & 0.78 & 7.47 & 5.15 & 6.40 \\
EUVSKL75 & 0.98 & 1.17 & 14.58 & 10.62 & 8.53 \\
Avg. & 0.99 & 0.98 & 11.02 & 7.88 & 7.47 \\
\hline
\end{tabular}

ozone data, 'DO3' is for Dobson ozone data, and ' $\mathrm{S}$ ' is for simple model. $R^{2}$ is the square of the correlation coefficient, ME is mean error, RMSE is root mean square error, MAE is mean absolute error, and MAPE is mean absolute percentage error.

\section{UV Model}

Two versions of a regression model were devel oped for UVI prediction in Bangkok and Songkhla. The coefficients which come from the study are given in Tables 6 and 7 . Figures 4 and 5 comparethe measured and calculated Erythemal UV values in Bangkok and Songkhla. At very high values of Erythemal UV, the model underestimates the measured values by about $15 \%$. This suggests that further investigation of the modeling of extreme values is needed.

Daily and seasonal variations in the ratio of the

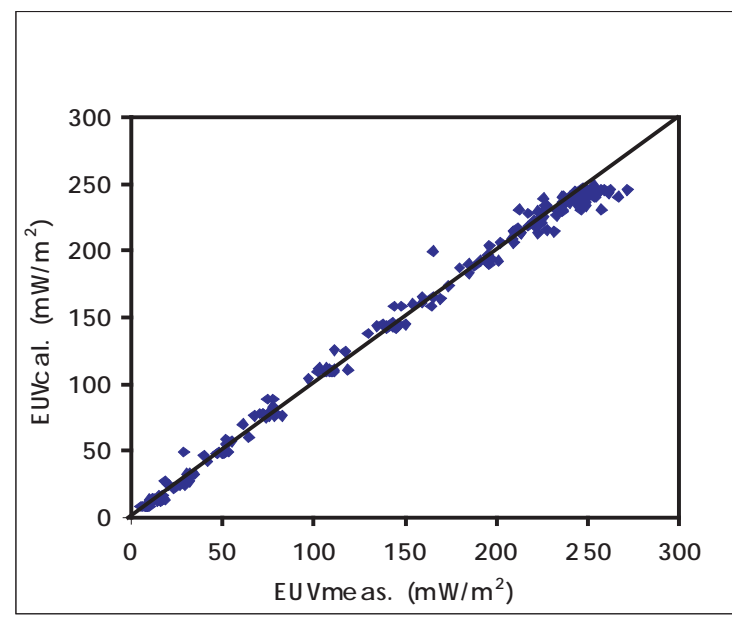

Fig 4.Comparison between measured and calculated Erythemal UV at Bangkok.

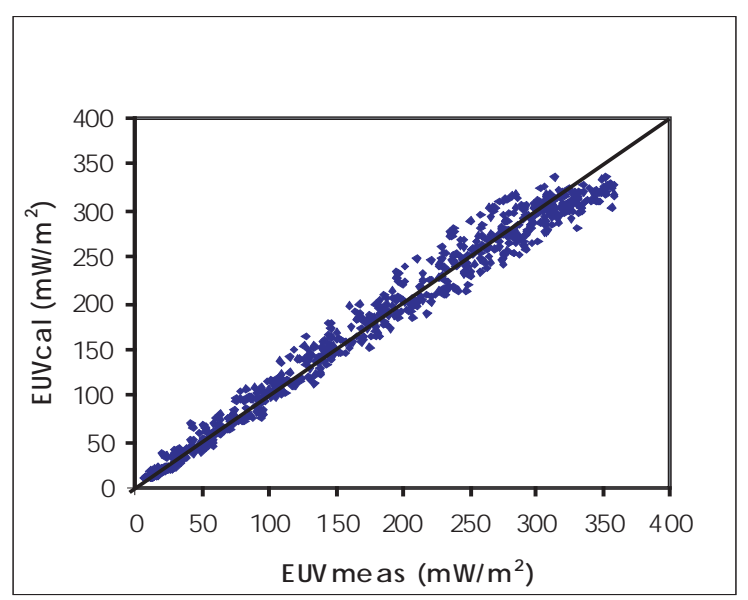

Fig 5.Comparison between measured and calculated Erythemal UV in Songkhla.

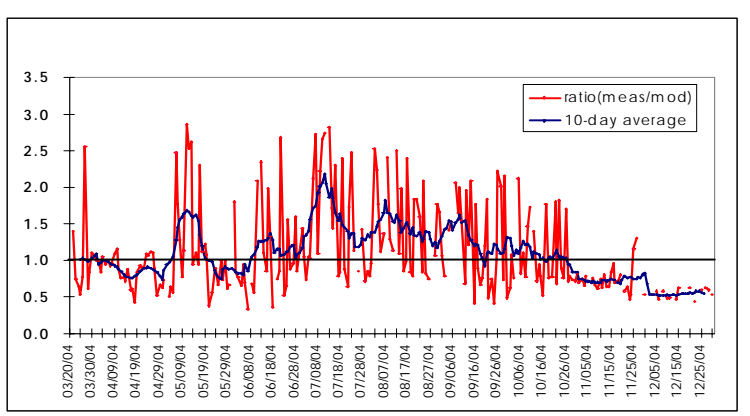

Fig 6. Ratio of measured to modeled UVI at noon, in Bangkok, in 2004, after ap plying CM F. Daily variation is shown by actual data. Seasonal variation is shown by 10 -day averages.

measured to modeled UVI, adjusted by the CMF, at noon, during 2004 are illustrated in Fig. 6. There is a tendency for the application of the CMFs to underestimate the UV Indices during the wet season (June-October). 


\section{STARsci Model}

An ad ditional tool for UV forecasting istheSTARsci ${ }^{14}$ radiative transfer model which is used in parallelwith the statistical model and for other locations where the statistical model is not available. The STARsci model was developed at the Meteorologisches Institut der Universität München in 1999. TheSTARsci model uses variable data sets for the description of theatmosphere as vertical profiles and totals (where appropriate) of ozone, nitrogen dioxide, sulfur dioxide, pressure, temperature, relativehumidity, aerosol extinction, and liquid water content for homogeneous cloud layers, as well as solar zenith angle and ground albedo. The calculations are carried out for irradianceand integrals with respect to wavelength, especially for erythemal dose from $280 \mathrm{~nm}$ to $700 \mathrm{~nm}$.

\section{UV Forecasting}

The UVI forecast issued daily by the Thai Meteorological Department is in the form of a map showing theUVI values calculated from the predicted clear sky EUV $V_{0}$ at four locations in Thailand as in Fig. 7. TheUVI valuesarearranged in five exposurecategories as in Table 8.

When the sky is cloudy the predicted values of the clear sky UVI can be reduced by a CM F, as in Table 1, to give predicted UV Indices under various sky cloudiness conditions in addition to the clear sky prediction.

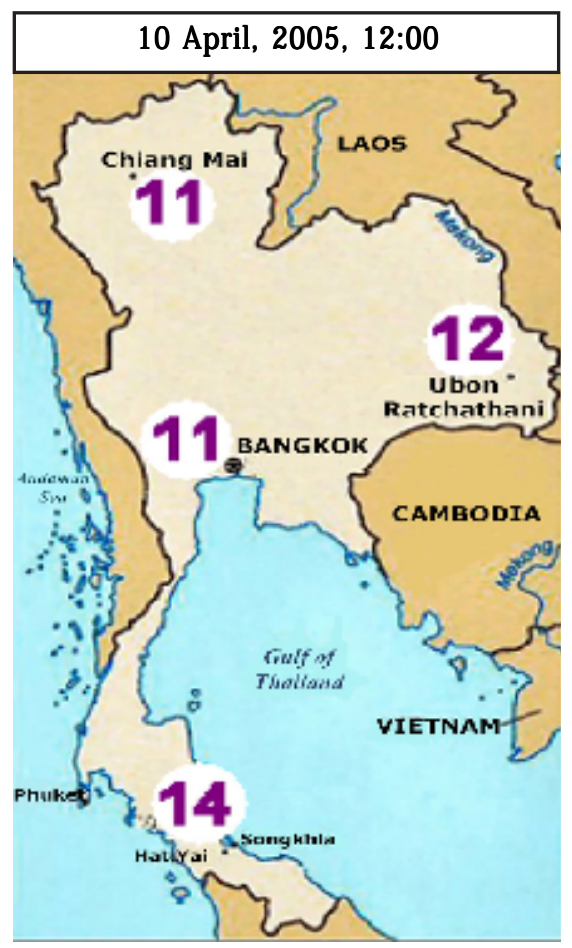

Fig 7. A map of UV Index Forecast for clear sky ${ }^{15}$.
Table 8. Exposure Categories.

\begin{tabular}{cc}
\hline Exposure category & UVI range \\
\hline Low & $<2$ \\
Moderate & 3 to 5 \\
High & 6 to 7 \\
Very High & 8 to 10 \\
Extreme & $11+$ \\
\hline
\end{tabular}

\section{Discussion}

The models presented in this paper for predicting erythemal UV are valid for zenith angles less than 75 degrees and AOD ( $\left.\tau_{\text {aer }}\right)$ in the range 0.2 to 0.5 under an average clear sky condition. M odels for a completely clear sky with $\tau_{\text {aer }}<0.2$, and for a polluted sky with $\tau_{\text {aer }}$ $>0.5$, areal so available, but thesemodel sare not in use. Completely clear skies are rare, and although polluted skies often occur in the dry season, the average clear sky model is used with polluted skies to avoid the risk of underestimating theerythemal UV. Research directed towards the development of good AOD predictions would help to improve UVI forecasts.

Predicting the UVI by regression models is a convenient and good qual ity tool. Under air pollution conditions it may give an overestimation, and under a completely clear sky the result can be an underestimation. The challenge in UV forecasting is not clear sky calculation but applying modification factors. W hatever models are used, the uncertainty is in the unpredictability of aerosols and the dynamics of clouds, which change hour-to-hour or day-to-day. Therefore further study on these factors is necessary.

\section{Concusion}

The total ozone and UVI can be predicted successfully by regression models which werecreated for the typical climate of Thailand. There are four versions of an ozone model for Chiangmai, Ubon Ratchathani, Bangkok and Songkhla, and two versions of UV model for Bangkok and Songkhla.

The total ozone model in this study uses fifteen coefficients in a linear regression formula, and three coefficients for asimpleformula. Thetotal ozonemodel is to be used on days when the upper air observations areavailable, and thesimplemodel is to beused on the days without upper air data. The output of ozone forecasts will be the input of the UV models.

Two versions of the empirical UV model areused to predict the level of erythemal UV for clear skies in Bangkok and Songkhla. For the northern part of Thailand, Chiangmai, and north-eastern part, Ubon 
Ratchathani, the radiative transfer STARsci model is used to estimatethelevel of Erythemal UV by choosing approp riate input parameters. The EUV $V_{0}$ output for a clear sky is converted to aUVI for issuing to the public at noon daily. UV Indices adjusted with the CM F s are provided for usein different sky cloudinessconditions.

The average accuracies of all the models are acceptableas the square of the correlation coefficients $\left(R^{2}\right)$ for the ozone and UV models are 0.88 and 0.99, while the mean absolute percentage error of the residuals are $1.5 \%$ and $7.5 \%$ respectively.

\section{AC KNOWEDGEMENTS}

This study was supported by ascholarship from the Joint Graduate School of Energy and Environment, King Mongkut's U niversity of Technology Thonburi. The data set was contributed by the Meteorological Department, SongkhlaSouthern M eteorological Centre and the NASA. Thanks are due to the Czech $\mathrm{HydroM}$ eteorological Institute-Solar and Ozone Observatory for the software for the Brewer ozone and UV data analysis, and the International Ozone Service for their maintenance and calibration of the instruments.

\section{RefERENCES}

1. Sudhibrabha S (2004) Ultraviolet Forecasting in Thailand. A Thesis report of The Joint Graduate School of Energy and Environment at King Mongkut's University of Technology Thonburi $2^{\text {nd }}$ Semester 2003.

2. Sudhibrabha S, Exell RHB, and Sukawat D (2004) Preliminary Forecast of Ozone and UV over Thailand, Proceedings of the XX Quadrennial Ozone Symposium, 1-8 June 2004, Kos, Greece, 1157-58.

3. Sudhibrabha S, Exell RHB, and Sukawat D (2004) Ozone and UVI Forecasting, Proceedings of the JGSEE and Kyoto University Joint International Conference on "Sustainable Energy and Environment (SEE)", 1-3 December 2004, Hua Hin, Thailand, 766-70.

4. ICNIRP (1996) Global Solar UVI. A Joint Recommendation of WHO, WM O, UNEP, ICNRP and IARC International Commission on N on-Ionizing Radiation Protection, Oberschleissheim.

5. Seckmeyer G, Bais A, Bernhard G, Blumthaler M, Booth CR, Disterhoft $P$, Eriksen $P, M c k e n z i e ~ R L$, et al (2000) Instruments to measure solar ultraviolet radiation Part 1: Spectral instruments. WMO Global Atmosphere Watch 125.

6. CIE (1987) A Reference Action Spectrum for Ultraviolet Induced Erythema in Human Skin, CIE J.6, No.1, 17-22.

7. Vanicek K, Frei T, Litynska Z, and Schmalwieser A (2000) UV-Index for the Public, COST-713 Action 'UVB Forecasting', Brussels.

8. WHO, WMO, UNEP and ICNRP (2002) Global Solar UVI. A Joint Recommendation of the WHO, WMO, UNEP and ICNRP, Geneva.

9. Silva AA, and Kirchhoff VWJH (2002) Brewer spectrophotometer UV-B measurements for aerosol optical thickness determinations during biomass burning, http:// www.aero.jussieu.fr/ sparc/SPARC2000_new/PosterSess4/
DaSilvaA_A/.

10. Marenco $\bar{F}$, Sarra A, and Luisi JD (2002) Methodology for determining aerosol optical depth from Brewer 300-320 nm ozone measurements, Applied Optics, Vol.41, No.9, 180514.

11. Hansen, J. and P. Travis (1974) On Rayleigh scattering, Space Science Reviews 16, 527-610. Cited by Silva \& Kirchhoff ${ }^{9}$.

12. Bais AF, Tourpali K, Balis D, Meleti C, Zerefos CS (2001) UV-B Forecasting in Greece (Private communication).

13. Burrows WR, Vallee M, Wardle DI, Kerr JB, Wilson LJ, and Tarasick DW (1994) The Canadian Operational Procedure for Forecasting Total Ozone and UV Radiation, Met Apps 1, 247-65.

14. Schwander $H$, Koepke $P$, Ruggaber A, Nakajima T, Kaifel A, and Oppenrieder A (2001) System for Transfer of Atmospheric Radiation General Model Description (STAR), http://www. meteo.physik.uni-muenchen.de/strahlung/ uvrad/Star/describe.html.

15. Meteorological Department (2004) UVI Forecast, http:// www.tmd.go.th/ ozone/UV_index.htm. 